\title{
하천재해위험지구 투자우선순위 결정기법 개발 Development of Decision Method for Investment Priority of River Flooding Disaster Risk Zone
}

\author{
이태우* - 주홍준** · 김보란*** · 김동현**** . 김수전***** · 김형수****** \\ Lee, Taewoo*, Joo, Hongjun**, Kim, Bo Ran***, Kim, Donghyun***, Kim, Soojun*****, \\ and Kim, Hung Soo*****
}

\begin{abstract}
In disaster management, the importance of the prevention-preparedness phase has increased as compared to the response-recovery stage in the past. In general, the state has allotted a large-scale budget for disaster prevention projects that needs to be invested efficiently in areas where it is required: that is, primarily in the order of high feasibility in flood risk zones. This study tries to suggest a decision method for investment priority of river flooding disaster prevention projects for risk zones. Evaluation factors such as the benefit-cost ratio $(\mathrm{B} / \mathrm{C})$, flood risk, residents' discomfort, past damage history, and alienated class are selected. Analytic Hierarchy Process (AHP) is applied to estimate the weight of each factor and sub-factor after the questionnaire survey. The applicability of the proposed method to the target area is evaluated.
\end{abstract}

Key words : Disaster Prevention Project, River Flooding Disaster, Investment Priority Decision

\section{요 지}

재난관리에 있어서 과거의 대응-복구 단계에서 최근에는 예방-대비 단계의 중요성이 증가하고 있다. 이에 따라 행정안전부는 재해를 예방하고 경감하기 위해 재해예방사업을 추진하고 있다. 재해예방사업은 대규모의 국가예산이 투입되는 사업으로, 예산이 필요한 지역에 최대한 효율적으로 투입되어야할 필요가 있다. 재해 예방 사업비는 각 지자체 내에서 선정된 위험지구를 대상으로 사업의 타당성(투자우선순위)이 높은 순으로부터 우선 투자된다. 본 연구에서는 재해예방사업 중 하천재해위험지구 정비사업의 효율적 집행을 위한 하천재해위험지구 투자우선순위 결정기법을 제시하고자 한다. 각 평가항목으로 비용편익비, 재해위험도, 주민불편도, 재해저감효과 등의 지표를 선정하였다. 선정한 지표에 대하여 AHP 분석을 실시한 후 각각 가중치를 산정하였다. 산정한 가중치를 적용하여 대상지역에 대한 적용성 평가를 수행하였다.

핵심용어 : 재해예방사업, 하천재해, 투자우선순위

*정회원, 인하대학교 토목공학과 석사과정(E-mail: dfd0d7cf@nate.com)

Member, Master's Course, Department of Civil Engineering, Inha University

**정회원, 인하대학교 수자원시스템연구소 박사후연구원

Member, Post-Doc., Water Resource System Research Institute, Inha University

***콜로라도 주립대학교 토목공학과 박사과정

Doctor's Course, Department of Civil Engineering, Colorado State University

****정회원, 인하대학교 토목공학과 박사과정

Member, Doctor's Course, Department of Civil Engineering, Inha University

*****교신저자, 정회원, 인하대학교 사회인프라공학과 조교수(Tel: +82-32-860-7563, Fax: +82-32-876-9787, E-mail: sk325@inha.ac.kr)

Corresponding Author, Member, Assistant Professor, Department of Civil Engineering, Inha University

******정회원, 인하대학교 사회인프라공학과 교수

Member, Professor, Department of Civil Engineering, Inha University 


\section{1. 서 론}

최근 재난관리는 과거 대응-복구 위주의 정책집행 개념에 서 사전단계인 예방-대비 단계의 중요성이 날로 부각됨에 따라 사전 안전관리 분야가 매우 중요시되고 있다. 우리나라 의 경우 행정안전부에서 매년 태풍과 집중호우 등 자연재난 으로 인한 피해를 예방하고 경감하기 위하여 재해예방사업 을 추진하고 있다. 재해예방사업은 자연재해저감 종합계획 에서 지정된 위험지구들을 대상으로 진행하며, 지정된 여려 위험지구 중 타당성 평가를 통하여 우선순위가 높은 지구 순으로 예산을 투입하여 사업을 진행한다. 위험지구 타당성 평가는 해당 위험지구의 예방사업에 대한 효율성과 형평성, 긴급성 등의 평가항목 등을 통하여 투자우선순위를 결정한 다(MOIS, 2018). 1995년부터 시작된 재해예방사업은 해가 지날수록 그 규모가 커져 2009년 이후부터는 국비와 지방비 를 포함하여 약 1 조 수천억 원의 막대한 예산이 투입되고 있다. 이러한 대규모의 재해예방사업 예산은 최종적으로 각각의 지방자치단체에 배분되며, 각각의 지방자치단체는 자연재해대책법 제 16 조(자연재해저감 종합계획의 수립), 제 16 조의2(자연재해저감 시행계획의 수립 등)에 의거하여 수 립한 자연재해저감 종합계획을 통해 재해예방사업을 실시 한다. 대규모의 예산이 투입되는 만큼 재해예방사업이 효율 적으로 이루어져야할 필요가 있다. 현재 행정안전부에서 시군 규모의 지방자치단체를 대상으로 '시·군 등 자연재해 저감 종합계획 세부수립기준(Standards of the comprehensive plan for flood storm damage reduction)'을 고시하였으며 세부수립기준에 자연재해위험지구의 투자우선순위를 결정 하는 방법론을 제시하였다. 그러나 제시된 투자우선순위 결정 방법론은 정량적이고 타당한 투자우선순위를 결정하 는 데 한계가 있다.

국외의 선행연구로 미국의 연방재난관리청(FEMA)에서 는 재난에 대핸 피해 규모를 추정하여 지역별 예방사업 투자 우선순위까지 결정하는 프로그램인 Hazus-MH를 2006년에 개발하였으며 현재까지 사용하고 있다. Aerts et al. (2018)은 재난 발생에 따른 개인과 기업, 정부기관의 행동에 의한 영향을 정량적으로 평가하여 홍수위험평가의 지표로서의 활용 가능성을 제시하였다. Loos and Rogers (2016)는 홍수 취약성 평가를 위해 특정 지역사회의 이해관계자가 참여하여 대안을 평가할 수 있도록 상호작용적 의사결정 구조를 설계 하고 평가하였다.

국내의 선행연구로 Kim et al. (2018)은 수문 - 기상학적 인자와 사회 - 경제학적 인자로 구성된 수재해 취약성 지수 인 Water Disaster Vulnerability Index (WDVI)를 제시하고 아시아 몬순 지역의 30 개국에 대해 평가하였다. Joo et al. (2018)은 홍수피해잠재능(Potential Flood Damage)과 홍수 위험도 지표를 고려하여 홍수 취약성을 평가하는 지표를 추출 후 $\mathrm{AHP}$ 기법과 엔트로피(Entropy) 이론을 통하여 도출
한 지표의 가중치 산정 후 산정한 가중치를 반영한 통합 홍수 취약성 지수를 제시하였다. Kim and Lee (2017)는 담당 공무원 및 관련 전문가 설문을 통해 재해예방사업의 중요 성공요인을 선정하고 각 요인의 $\mathrm{AHP}$ 가중치를 산정하 였다. Ryu and Han (2016)은 사면재해의 투자우선순위 결정 을 위한 Fuzzy 추론 기반 사면의 위험도 평가 방법을 제시하 였다. Choi and Lee (2015)는 2종 저수지를 대상으로 시행한 저수지 안전점검 결과를 토대로 저수지 안전성 평가와 댐하 류 및 주변지역 재해영향평가를 고려한 투자우선순위 결정 지원방안을 제시하였다. Lee et al. (2013)은 산업재해 예방사 업의 심츨평가를 위한 평가항목을 도출하여 $\mathrm{AHP}$ 기법을 통해 평가항목별 가중치를 설정하였다. Heo et al. (2013)은 자연재해위험지구의 과거 재해 이력 대비 총사업비로부터 비용편익비를 산정하여 자연재해위험지구 정비사업의 사후 투자효과를 분석하였다. Kim et al. (2006)은 다기준의사결정 기법을 통하여 댐 사업 투자우선순위를 위한 평가기법을 개발하였고 재개발을 계획하고 있는 댐에 적용하였다.

기존의 선행 연구에서는 홍수 취약성 지표 등 홍수 피해에 대한 공학적인 지표 또는 피해 경감에 대한 경제적 지표만을 제시하였으나 실질적인 재해예방사업의 투자우선순위 결정 을 위한 기준을 제시하고 있지 않다. 이에 본 연구는 기존의 자연재해위험지구 중 하천재해위험지구의 투자우선순위 결정기법을 각 평가항목에 대해 분석하고, 각 평가항목을 개선하는 방안을 제시하고자 한다. 이로 인해 하천재해위험 지구 정비사업 시 효율적인 방재예산 집행을 지원할 수 있을 것으로 기대된다.

\section{2. 자연재해위험지구 투자우선순위 결정기법}

\section{1 국내 자연재해위험지구 투자우선순위 결정기법}

국내의 재해예방사업은 자연재해대책법에 따라 행정안 전부에서 자연재해위험개선지구 정비사업을 추진하고 있으 며 최상위 계획으로 각 시·도 및 시·군·구 지방자치단체 에서 자연재해저감 종합계획을 수립하여 추진하고 있다. 자연재해저감 종합계획을 수립하기 위한 자연재해위험지구 (Natural disaster risk zone)의 투자우선순위 결정을 위한 평가항목은 크게 기본적 평가항목, 부가적 평가항목으로 나뉜다. 기본적 평가항목은 효율성, 형평성, 긴급성으로 나 뉘며, 부가적 평가항목은 지속성, 정책성, 계획성으로 나닌 다. 각 평가항목 및 배점은 Table 1 과 같다.

효율성(efficiency)의 비용편익비(B/C) 항목은 재해예방사 업을 수행함으로써 재해가 발생할 시 발생하게 될 피해액을 예방한다는 차원에서 편익(Benefit)으로 대체하고 이를 재해예 방사업에 투자된 비용(Cost)으로 나눔으로써 산정할 수 있다. $\mathrm{B} / \mathrm{C}$ 가 1 보다 크면 대체로 사업의 타당성이 있다고 판단한다. 편익은 직접피해만을 산정하며, 산정하는 방법론으로는 간편 법(Simple method), 개선법(Regression analysis method), 다차 
Table 1. Decision Method for Investment Priority of Natural Disaster Risk Zone

\begin{tabular}{|c|c|c|c|}
\hline & Evaluation factors & Points & Evaluation criteria \\
\hline efficiency & $\begin{array}{c}\mathrm{B} / \mathrm{C} \\
\text { (Benefit / Cost) }\end{array}$ & 15 & $\begin{array}{l}\text { - } B / C \geq 3: 15 \text { points } \\
\text { - } 2 \leq B / C<3: 12 \text { points } \\
\text { - } 1 \leq B / C<2: 9 \text { points } \\
\text { - } 0.5 \leq B / C<1: 6 \text { points } \\
\text { - } B / C<0.5: 3 \text { points }\end{array}$ \\
\hline equity & Past damage history & 25 & - Private property damages in recent 5 years \\
\hline \multirow{4}{*}{ urgency } & \multirow[t]{2}{*}{ Disaster risk } & 20 & $\begin{array}{l}\text { - Hazard risk class A: } 20 \text { points } \\
\text { - Hazard risk class B: } 10 \text { points } \\
\text { - Hazard risk class C: } 5 \text { points }\end{array}$ \\
\hline & & 10 & $\begin{array}{l}\text { - Human damage by natural disaster (death): } 10 \text { points } \\
\text { - Human damage by natural disaster (injury): } 5 \text { points }\end{array}$ \\
\hline & Resident discomfort & 20 & $\begin{array}{l}\text { - Ratio of residential population }(P) \text { to area of risk zone }(A): P / A \\
\text { - } P / A \geq 100: 20 \text { points } \\
\text { - } 50 \leq P / A<100: 16 \text { points } \\
\text { - } 20 \leq P / A<50: 12 \text { points } \\
\text { - } 5 \leq P / A<20: 8 \text { points } \\
\text { - } P / A<5: 6 \text { points }\end{array}$ \\
\hline & $\begin{array}{l}\text { Elapsed years } \\
\text { since designation } \\
\text { as Risk zone }\end{array}$ & 10 & $\begin{array}{l}\text { - Elapsed years } \geq 10: 10 \text { points } \\
\text { - } 5 \leq \text { Elapsed years }<10: 8 \text { points } \\
\text { - } 2 \leq \text { Elapsed years }<5: 6 \text { points } \\
\text { - } 1 \leq \text { Elapsed years }<2: 4 \text { points } \\
\text { - Elapsed years }<1: 2 \text { points }\end{array}$ \\
\hline Total & & 100 & \\
\hline
\end{tabular}

원법(Multi- Dimensional Flood Damage Assessment)이 있 다. 간편법은 편익을 구성하는 직접피해액을 산정함에 있어 농경지· 공공시설물·기타 피해액 등을 사업지구의 농산 물 피해액과 관련시켜 산정하는 방법이며, 개선법은 간편법 의 방밥론에 도시유형별 침수면적-피해액 관계식을 설정하 여 피해액을 산정하는 이론을 추가한 방법이다. 다차원법은 대상지역의 $100 \%$ 피해규모를 산정한 후 침수심 조건에 따라 피해율을 적용하여 예상 홍수 피해액을 산정하는 방법 이다. 형평성(equity)의 피해이력지수(Past damage history) 항목은 최근 5 년 동안의 사유재난 피해에 대하여 피해유형 이나 항목에 따른 가중치와 수량을 통하여 산정할 수 있다. 피해항목은 사망 - 실종·부상자 및 이재민 등의 인명피 해, 주택피해, 농업 - 축산업 - 수산업 등의 산업시설 및 농축수산물을 대상으로 한다. 긴급성(urgency)의 재해위험 도(Disaster risk) 항목은 해당 위험지구의 자연재해에 대한 위험등급과 인명피해 이력으로부터 평가점수를 산정한다. 평가점수 산정을 위한 위험등급을 나누는 기준은 Table 2 와 같다. 위험등급은 재해 발생 시 피해를 입는 대상에 따라 분류된다. A 등급은 인명피해, $\mathrm{B}$ 등급은 건축물 피해, $\mathrm{C}$ 등급은 기반시설 및 농경지피해의 발생 이력이 있거나 발생 우려가 있을 시 부여된다.
Table 2. Classification of Hazard Risk

\begin{tabular}{|c|c|}
\hline Class & Hazard risk classification \\
\hline A & $\begin{array}{l}\text { Areas with high risk of human damage in } \\
\text { the event of a disaster }\end{array}$ \\
\hline B & $\begin{array}{l}\text { Areas where buildings (housing, store, public) } \\
\text { were damaged of are likely to be damaged } \\
\text { in the event of a disaster }\end{array}$ \\
\hline $\mathrm{C}$ & $\begin{array}{l}\text { Areas where infrastructures (industrial } \\
\text { complexes, railways, roads) are likely to be } \\
\text { damaged in the event of a disaster } \\
\text { or } \\
\text { Farmland where flood were occurred of are } \\
\text { likely to be flooded }\end{array}$ \\
\hline
\end{tabular}

주민불편도(Residents discomfort) 항목은 해당 위험지구 내에 거주하는 주민 수를 위험지구의 면적으로 나누어 산정 된 인구밀도로부터 평가점수를 산정한다. 인구밀도 산정은 자연재해저감 종합계획 수립 시 지정된 자연재해위험지구 의 지도 자료와 통계지리정보서비스(SGIS)에서 제공하는 해당 행정구역의 인구통계 집계구 경계 지도 자료를 활용한 다. 지구선정 경과년수(Elapsed years since designation as Risk zone) 항목은 해당 위험지구가 위험지구로 지정된 이후 
경과된 년 수로부터 평가점수를 산정한다. 시· 군 내 지정된 자연재해위험지구를 대상으로 각각의 평가항목별 점수를 산정한 후 합산한 점수로부터 높은 순으로 투자우선순위를 결정한다.

\section{2 기존 자연재해위험지구 투자우선순위 결정기법의 문제점}

기존의 자연재해위험지구 투자우선순위 결정기법은 재 해에 대한 긴급성 뿐 만 아니라 효율성 및 형평성까지 고려한 평가항목으로 구성되어있다. 그러나 기존의 이러한 결정기 법에는 다음과 같은 한계점이 있다.

먼저 효율성 항목의 경제성 평가를 위한 '비용편익비' 산정 시 편익 산정을 위한 세 가지 방법론 중 현행 자연재해저 감 종합계획 세부수립기준에서는 개선법을 채택하는 것을 원칙으로 하고 있다. 그러나 개선법은 침수면적에 따른 피해 액만을 고려하기 때문에 실제 홍수피해액에 영향을 미치는 침수심과 침수기간에 고려하지 못한다. 또한 재해연보를 기초로 산정한 홍수피해 평균주기로부터 피해를 산정하기 때문에 대상지역에 대한 홍수빈도를 고려하지 못한다는 한계점이 있다(Choi et al., 2006). 기존의 개선법에서 고려하 고 있는 직접피해 산정 항목은 Table 3 과 같다.

Table 3. Direct Damage List of Existing Method

\begin{tabular}{c|c}
\hline Classification & Damage list \\
\hline \multirow{3}{*}{ Personal assets damage } & Buildings \\
\cline { 2 - 2 } & Farmland \\
\cline { 2 - 2 } Public facilities damage & Crops \\
\hline \multirow{2}{*}{ Human damage } & Public facilities \\
\cline { 2 - 2 } & Casualties \\
\hline
\end{tabular}

긴급성 항목 중 ‘재해위험도' 평가항목은 위험등급 항목 과 인명피해 항목으로 세분화 되는데, 이중 인명피해 항목은 피해이력지수 항목에서도 고려되고 있으므로 중복 우려가 있다. 또한 위험등급 항목은 재해 시 인명피해나 건축물, 기반시설의 피해 발생 우려에 따라 등급이 부여되는데 이는 재해 시 예상되는 사유재산 - 공공재산의 피해액을 반영하 는 '비용편익비' 항목과 중복될 우려가 있다.

다음으로 긴급성 항목 중 ‘주민불편도' 평가항목 산정 시 단순 집계구 경계 자료 활용 시 실제 거주지역을 반영하지 못할 우려가 있다. 단순 집계구경계 자료만으로 거주인구를 산정할 시 해당 위험지구 내에 주거지역을 고려하지 못하거 나 실제로 거주하고 있는 인구가 없을 시에도 인구가 집계될 우려가 있다.

또한 ‘지구선정 경과년수’ 평가항목의 경우 해당 지구가 위험지구로 지정된 기간이 오래될수록 평가점수가 높아지
게 된다. 그러나 매년 진행되는 재해예방사업 차원에서 지구 로 지정된 후 많은 시간이 경과하였다는 것은 오히려 긴급성 이 낮기 때문이므로 사업이 신속히 진행되지 않고 후 순위로 미루어졌다고 볼 수 있다.

마지막으로, ‘비용편익비’ 및 ‘주민불편도' ‘지구선정 경 과년수 평가항목의 점수 배점 방식은 해당 평가항목을 산정 한 값에 대해 5 개의 등급으로 나누어 등급에 따라 점수를 부여한다. 이러한 절대평가 방식의 문제점은 해당 평가항목 이 임계값을 벗어나게 되는 경우 값이 많이 차이가 남에도 불구하고 모두 같은 점수를 부여하게 된다는 것이다. 결과적 으로 위험지구별 타당성 평가의 변별력이 많이 하락하는 결과를 초래하게 된다.

\section{3 하천재해위험지구 투자우선순위 결정기법 제시}

본 연구에서는 기존의 자연재해위험지구 투자우선순위 결정기법의 문제점을 보완하고 기존에 반영하지 못한 평가 항목을 반영할 수 있는 투자우선순위 결정기법의 개선안을 제시하였다.

비용편익비 평가항목 산정방법은 기존에 적용되었던 방 법론인 개선법을 대체하여 다차원법(Multi-Dimensional Flood damage analysis, MD-FDA)을 적용하였다. 다차원법 은 개선법을 개선하여 행정구역 내 자산가치를 산정하고 자산의 공간적 분포를 고려한 침수편입율을 결정하여 침수 심에 맞는 피해율을 곱해서 직접피해를 산정하는 방법론이 다(Choi et al., 2006). 다차원법은 구간분할 회귀분석 및 다중회귀분석을 통하여 정확도를 높였고, 연평균피해액의 산정을 체계화하여 기존의 개선법의 문제점을 보완하였다. 다차원법으로 인한 직접피해 산정 시 고려되는 피해 항목은 Table 4에 제시하였다.

Table 4. Direct and Indirect Damage List of MD-FDA

\begin{tabular}{c|c}
\hline Classification & Damage list \\
\hline \multirow{2}{*}{ Residential area } & Structure \\
\cline { 2 - 2 } & Contents \\
\hline \multirow{2}{*}{ Agricultural area } & Farmland \\
\cline { 2 - 2 } & Crops \\
\hline Industrial area & Tangible assets and inventories \\
\hline \multirow{2}{*}{ Person } & Casualties \\
\cline { 2 - 2 } & Refugees \\
\hline
\end{tabular}

재해위험도 평가항목 산정방법은 기존 방법론을 대체하 여 홍수위험지도(Flood risk map)를 활용하는 방식을 제시하 였다. 홍수위험지도는 행정안전부에서 개발한 K-Flood 모형 의 호우피해 예측지도 결과자료를 활용하였다. 본 연구에서 는 하천재해 위험지구로 지정된 영역과 호우피해 예측지도 로부터 도출된 범람 예상지역이 겹치는 면적비 즉, 하천재해 
위험지구 면적 대비 위험지구 내 범람 예상지역 면적의 비를 산정하여 재해위험도 지표로 하였다.

주민불편도 평가항목은 자연재해위험지구 지도자료와 인구통계 집계구경계 지도자료를 활용하는 기존 방식에 추가로 토지피복도 지도자료를 활용한다. 산정순서는 다음 과 같다. 먼저 환경공간정보서비스(SGIS)에서 제공하는 세 분류 토지피복도 지도자료 중 주거시설에 해당하는 영역만 을 추출한다. 추출 후 해당 주거시설의 영역 및 인구통계 집계구경계 지도자료를 활용하여 주거지역의 인구를 산정 한다. 마지막으로 산정한 주거지역 인구와 해당 주거지역에 겹쳐지는 자연재해위험지구의 인구밀도를 산정한다. 이러 한 방법으로 주민불편도 평가항목 산정 시 자연재해위험지 구에 편입되어있는 실제 주거지역을 고려하는 효과를 기대 할 수 있다.

지구선정 경과년수 평가항목은 평가항목에서 제외하며 '재해저감효과(Disaster reduction effect)' 신규항목으로 대 체한다. 기존 재해예방사업의 투자우선순위 결정 시 일반적 으로 피해액 위주의 재해관리로 인해 금전적- 화폐 단위인 효과 이외의 저소득층이나 취약계층에 대한 고려가 부족한 실정이다. 이에 따라 기반시설 및 취약계층 등을 반영하는 재해저감효과 평가항목을 제시하였다. 재해저감효과 산정 시 고려되는 항목은 Table 5에 제시하였다.

Table 5. List of Disaster Reduction Effect

\begin{tabular}{c|c}
\hline Classification & Disaster reduction effect \\
\hline Regional & Land-use zoning \\
\hline Human & $\begin{array}{c}\text { Vulnerable population } \\
\text { (Preschooler, Senior, Disabled) }\end{array}$ \\
\hline Material & Year of construction completion \\
\hline Infrastructure & $\begin{array}{c}\text { Educational facility, Medical facility, } \\
\text { Cultural Heritage }\end{array}$ \\
\hline
\end{tabular}

평가점수 산정방법은 기존의 절대평가에 의한 산정방법에 서 상대평가에 의한 산정방법으로 대체하였다. 상대평가에 의한 방법은 표준화(Standardization) 및 정규화(Normalization) 를 적용하였다. 전체 위험지구에 대한 각각의 평가항목별 결과값의 평균 및 표준편차로부터 누적 정규분포함수를 도출한다. 도출한 누적 정규분포함수로부터 각각의 위험지 구별 평가항목 값에 해당하는 누적 정규분포함수 값을 평가 점수로 하였다.

마지막으로 평가항목별 배점은 다기준의사결정(MCDM) 방법론 중 Analytic Hierarchy Process (AHP) 분석을 통하여 재산정하였다. 재해예방사업의 우선순위 결정 특성상 수많 은 이해관계자의 주관적 만족을 위해 다양한 평가방법을 공평하고 객관적으로 고려해야하기 때문에 주관적 특성과 객관적 특성이 결합된 $\mathrm{AHP}$ 분석기법을 채택하였다. AHP
분석은 의사결정계층을 설정하고 계층구조를 구성하고 있 는 요소 간의 쌍대비교에 의한 판단을 통하여 가중치를 산정하는 방법이다(Saaty, 1977). 본 연구에서는 수자원 및 재난 분야 전문가 60 명을 대상으로 설문조사를 진행하였으 며 산정된 배점(가중치)은 Table 6에 제시하였다. 가중치는 피해이력지수, 재해저감효과, 재해위험도, 비용편익비, 주 민불편도 순으로 높게 산정되었다.

Table 6. Weight of Evaluation Factors

\begin{tabular}{c|c}
\hline Evaluation factors & Point (Weight) \\
\hline B/C & $11.7(0.117)$ \\
\hline Past damage history & $29.5(0.295)$ \\
\hline Disaster risk & $22.8(0.228)$ \\
\hline Resident discomfort & $11.4(0.114)$ \\
\hline Disaster reduction effect & $24.6(0.246)$ \\
\hline Total & $100(1.000)$ \\
\hline
\end{tabular}

Fig. 1 에 본 연구에서 도출한 기존 투자우선순위 결정기법 의 문제점 대비 개선한 방법론을 요약하였다.

\section{3. 하천재해위험지구 투자우선순위 결정기법 적용 및 결과}

\section{1 하천재해위험지구 투자우선순위 결정기법 적용}

본 연구에서는 2014년에 자연재해저감 종합계획이 수립 된 동두천시를 대상지역으로 설정하였다. 동두천시에는 20 개소의 하천재해위험지구가 지정되었으며 하천재해위험지 구 현황은 Table 7 및 Fig. 2와 같다. 20개소의 하천재해위험 지구에 2.3절에서 제시한 자연재해위험지구 투자우선순위 결정기법을 적용하였다.

기존 대비 개선 방법론의 비교를 위하여 비용편익비, 재해 위험도 주민불편도의 기존 방법론 및 개선 방법론의 평가지 표 산정결과를 Table 8에 나타내었다. 재해위험도 항목은 기존 결과와 개선안 결과의 정량적 비교를 위하여 기존의 재해위험도 평가지표를 $\mathrm{A}$ 등급의 20 점 대신 $1, \mathrm{~B}$ 등급의 10 점 대신 $0.5, \mathrm{C}$ 등급의 5 점 대신 0.25 로 변경하였다.

비용편익비 비교결과 기존 개선법에 의해 산정된 비용편 익비는 전반적으로 높게 산정되었음을 확인할 수 있다. 20 개 소 위험지구의 $\mathrm{B} / \mathrm{C}$ 의 평균은 24.26 으로 다소 높게 산정되었 다. 그리고 20 개소의 위험지구 중 1 개소를 제와한 19 개소 위험지구에서 $\mathrm{B} / \mathrm{C}$ 가 3 이상으로 산정되었다. $\mathrm{B} / \mathrm{C}$ 의 값이 1 이상인 경우 사업의 경제적 타당성이 있음을 의미하기 때문에 이러한 결과는 우선순위 결정이 다소 어려움이 있다. 또한 이러한 결과는 전체의 $95 \%$ 에 해당하는 위험지구에 비용편익비 평가점수 최고점(15점)을 부여하는 결과를 초래 한다. 이에 반해 다차원법에 의한 비용편익비는 개선법에 


\begin{tabular}{|c|c|c|}
\hline Problems of existing method & & Improvements of Improved method \\
\hline $\begin{array}{l}\text { Regression analysis method } \\
\Rightarrow \text { Flooding depth, term and frequency } \\
\text { is not considered }\end{array}$ & $\begin{array}{l}\text { Economic } \\
\text { Analysis } \\
\text { (B/C) }\end{array}$ & $\begin{array}{l}\text { Multi-Dimensioanl Flood Damage Assessment } \\
\text { \$ Considering flooding depth, term and frecuency } \\
\text { क Regression analysis considering the interval } \\
\text { division and Multiple regression analysis } \\
\text { क Systematization of average annual damage }\end{array}$ \\
\hline $\begin{array}{l}\text { Duplicate with other evaluation factors } \\
\text { - Damage History Index } \\
\text { - B/C }\end{array}$ & $\begin{array}{l}\text { Disaster } \\
\text { risk }\end{array}$ & $\begin{array}{l}\text { Change evaluation method } \\
\Rightarrow \text { Evaluate by using Flood risk map }\end{array}$ \\
\hline $\begin{array}{l}\text { Lack of accuracy } \\
\Rightarrow \text { Actual resident area is not considered }\end{array}$ & $\begin{array}{l}\text { Residents } \\
\text { discomforts }\end{array}$ & $\begin{array}{l}\text { Improved evaluation accuracy } \\
\Rightarrow \text { consider actual resident area } \\
\text { by using Land cover map }\end{array}$ \\
\hline $\begin{array}{l}\text { Lack of effectiveness } \\
\Rightarrow \text { May be highly evaluate for low risk area }\end{array}$ & $\begin{array}{l}\text { Elapsed years } \\
\text { since designation } \\
\text { as Risk zone }\end{array}$ & $\begin{array}{l}\text { - Delete the factor and Substitute by other factor } \\
\Rightarrow \text { Disaster Reduction effect. } \\
\text { which can consider the vulnerable }\end{array}$ \\
\hline $\begin{array}{l}\text { Scoring by rating } \\
\text { Lack discrimination evaluation } \\
\text { by disaster risk zones }\end{array}$ & $\begin{array}{l}\text { Scoring } \\
\text { method }\end{array}$ & $\begin{array}{l}\text { Scoring by standardization and normalization } \\
+ \text { Improve differential evaluation } \\
\text { by disaster risk zone }\end{array}$ \\
\hline
\end{tabular}

Fig. 1. Problems of Existing Method and Improvements of Improved Method

Table 7. River Flooding Disaster Risk Zones in Dongducheon City

\begin{tabular}{c|c||c|c}
\hline No. & Rive flooding disaster risk zone & No. & Rive flooding disaster risk zone \\
\hline 1 & Sangbong-am 1 & 11 & Gwangam-je 3 \\
\hline 2 & Anheung-je & 12 & Gwangam-je 4 \\
\hline 3 & Seonup-songnae & 13 & Motgol-cheon \\
\hline 4 & Bosan-je & 14 & Songnae-cheon \\
\hline 5 & Sangpae-je 1 & 15 & Anmal-cheon \\
\hline 6 & Dongdu-gol & 16 & Yogol-cheon \\
\hline 7 & Sangpae-je 2 & 17 & Dongmak-cheon \\
\hline 8 & Sangpae-je 3 & 18 & Anheung-cheon \\
\hline 9 & Gwangam-je 1 & 19 & Bongdong-cheon \\
\hline 10 & Gwangam-je 2 & 20 & Saemal-cheon \\
\hline
\end{tabular}

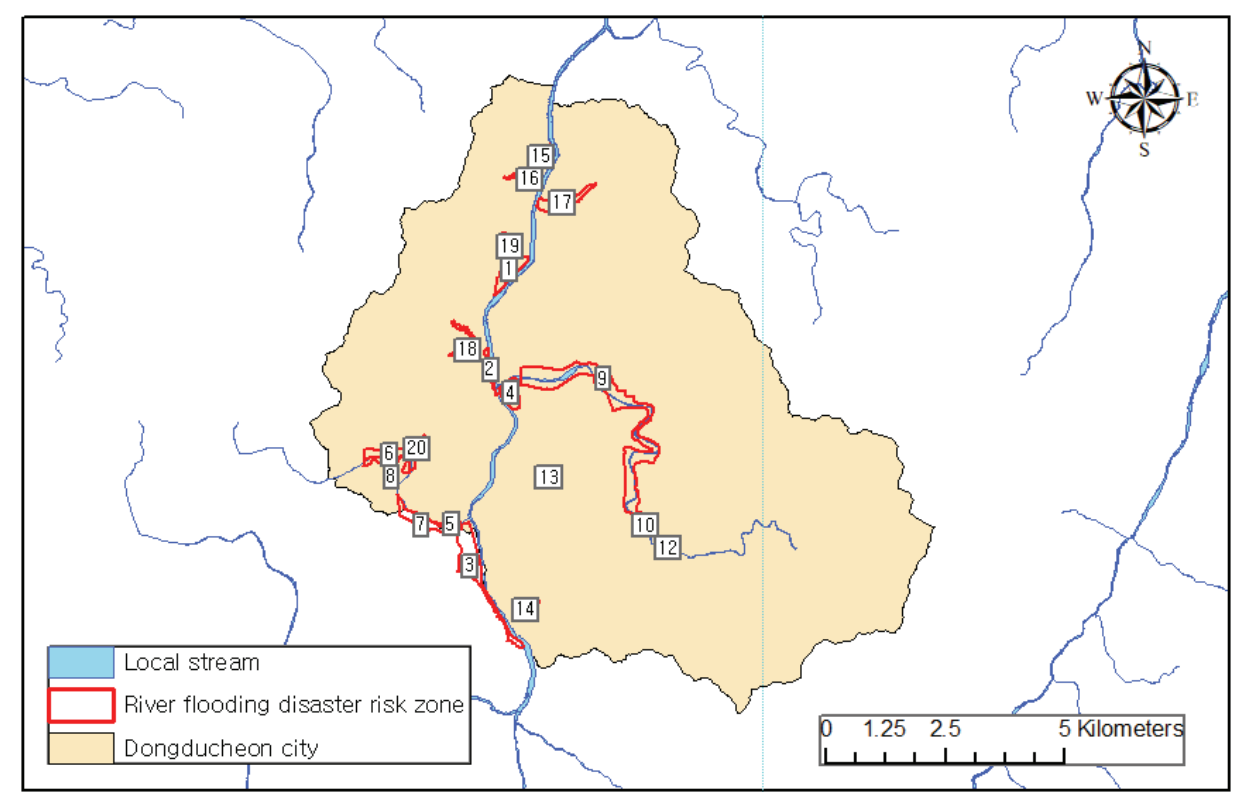

Fig. 2. Natural Disaster Risk Zones in Study Area (Dongducheon city) 
Table 8. Comparison the Results of Existing Method and Improved Method

\begin{tabular}{|c|c|c|c|c|c|c|c|}
\hline \multirow{2}{*}{ No. } & \multirow{2}{*}{ Name } & \multicolumn{2}{|c|}{$\mathrm{B} / \mathrm{C}$} & \multicolumn{2}{|c|}{ Disaster risk } & \multicolumn{2}{|c|}{ Residents discomfort } \\
\hline & & Existing & Improved & Existing & Improved & Existing & Improved \\
\hline 1 & Sangbong-am 1 & 21.18 & 0.012 & 0.25 & 0.01 & 13.43 & 7.06 \\
\hline 2 & Anheung-je & 6.57 & 0 & 0.25 & 0.03 & 0.71 & 10.92 \\
\hline 3 & Seonup-songnae & 7.95 & 1.412 & 1.00 & 0.05 & 2.26 & 0 \\
\hline 4 & Bosan-je & 7.89 & 3.301 & 0.25 & 0.87 & 13.00 & 0 \\
\hline 5 & Sangpae-je 1 & 33.82 & 0 & 0.50 & 0 & 5.11 & 0 \\
\hline 6 & Dongdu-gol & 18.28 & 0.475 & 0.25 & 0.51 & 1.87 & 0 \\
\hline 7 & Sangpae-je 2 & 7.56 & 0.107 & 0.50 & 0.20 & 2.26 & 0.06 \\
\hline 8 & Sangpae-je 3 & 17.06 & 0.004 & 0.50 & 0.20 & 1.77 & 0.97 \\
\hline 9 & Gwangam-je 1 & 0.80 & 0.058 & 0.25 & 0.35 & 1.89 & 0.14 \\
\hline 10 & Gwangam-je 2 & 21.97 & 0 & 0.50 & 0 & 30.17 & 24.28 \\
\hline 11 & Gwangam-je 3 & 173.10 & 0 & 0.50 & 0.05 & 0.63 & 13.80 \\
\hline 12 & Gwangam-je 4 & 98.45 & 0 & 0.50 & 0.11 & 0.45 & 0.46 \\
\hline 13 & Motgol-cheon & 20.37 & 0.195 & 0.5 & 0.20 & 109.86 & 129.87 \\
\hline 14 & Songnae-cheon & 5.11 & 0.539 & 1.00 & 0.12 & 1.49 & 21.20 \\
\hline 15 & Anmal-cheon & 6.27 & 0.437 & 1.00 & 0.45 & 1.00 & 4.42 \\
\hline 16 & Yogol-cheon & 7.06 & 5.473 & 0.25 & 0.29 & 1.00 & 3.13 \\
\hline 17 & Dongmak-cheon & 3.03 & 0.132 & 0.25 & 0.15 & 3.31 & 28.71 \\
\hline 18 & Anheung-cheon & 4.84 & 0.264 & 1.00 & 0.35 & 0.75 & 8.79 \\
\hline 19 & Bongdong-cheon & 6.76 & 0.509 & 0.50 & 0.08 & 13.62 & 40.36 \\
\hline 20 & Saemal-cheon & 17.21 & 1.675 & 0.50 & 0.07 & 2.75 & 9.38 \\
\hline
\end{tabular}

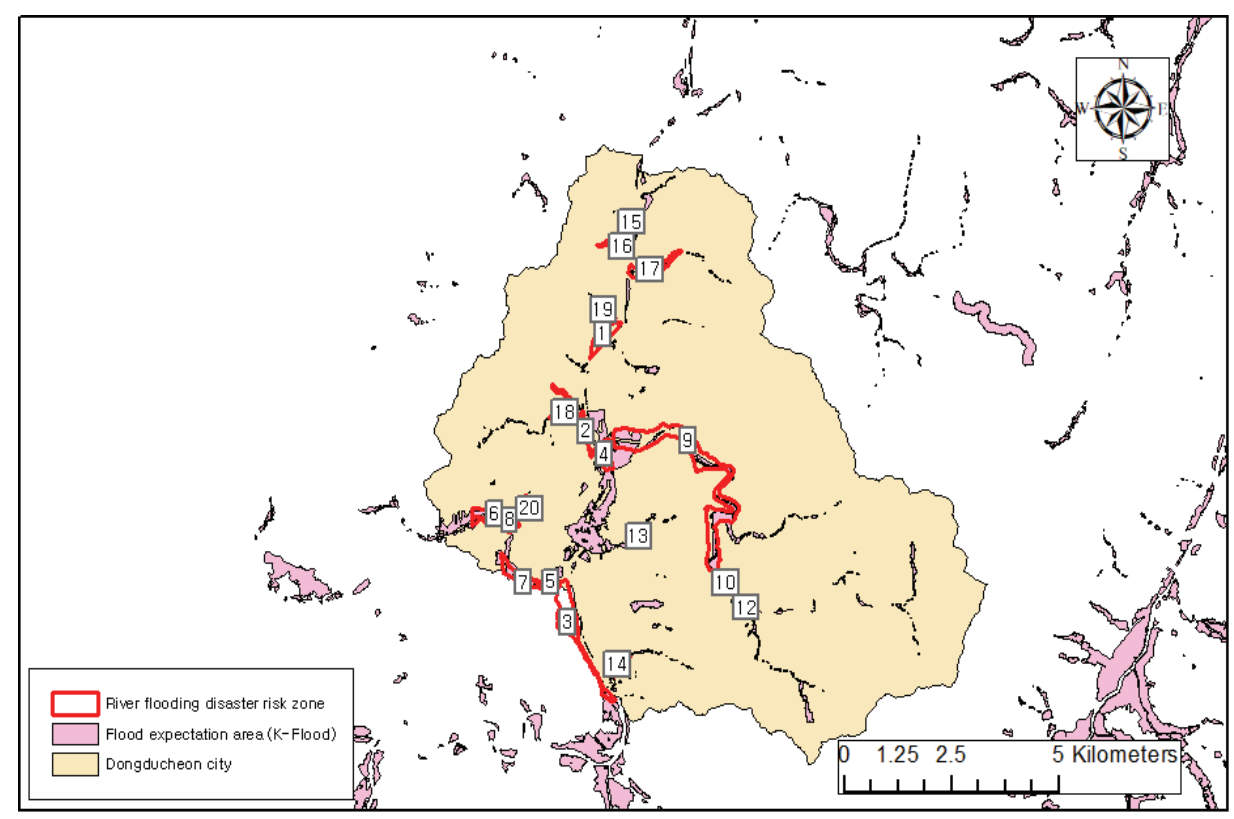

Fig. 3. Risk zone and flood expectation area map (Disaster risk)

비해 전반적으로 낮게 산정되었음을 확인할 수 있다. 20 개소 위험지구의 비용편익비 평균은 0.730 으로 산정되었다. 또한 비용편익비가 1 을 넘는 위험지구가 4 개소이며 5 개소의 위험 지구에서 비용편익비가 0 으로 산정되었다. 따라서 과다산정 된 기존 개선법의 비용편익비 결과에 비해 다차원법의 결과
는 비교적 변별력이 있다고 판단된다.

재해위험도 산정을 위한 하천재해위험지구 및 호우피해 예측지도는 Fig. 3에 나타내었다. 재해위험도 비교결과 각 지구별 기존 방법론인 위험등급에 따른 재해위험도와 개선 안의 홍수위험지도에 따른 재해위험도가 다르게 나타났다. 


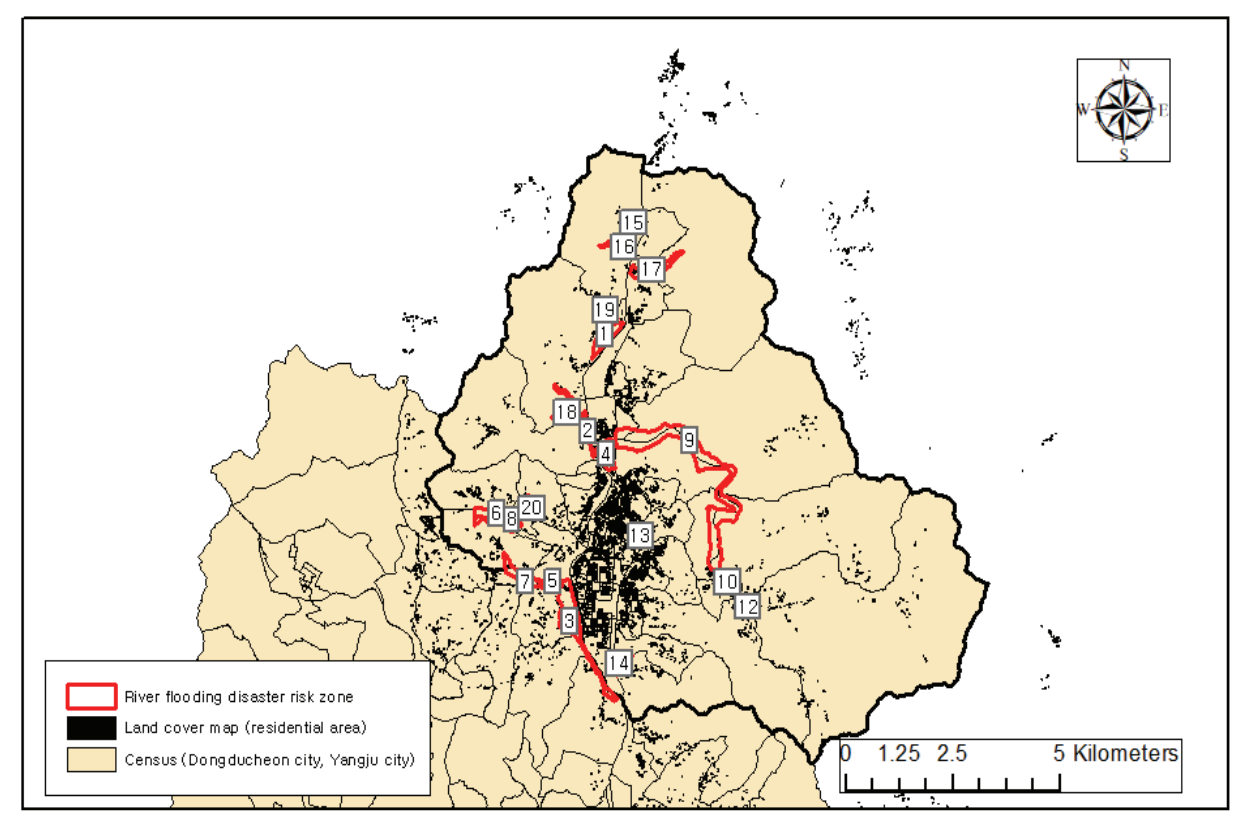

Fig. 4. Risk zone and residential area, census map (Resident discomfort)

특히 선업송내(Seonup-songnae) 위험지구는 기존 위험등급 이 $\mathrm{A}$ 등급으로 재해위험도가 높게 산정되었으나, 실제로는 위험지구 면적 대비 홍수위험지역 면적비 0.05 로 홍수위험 지역에 대부분 편입되지 않았다. 또한 보산제(Bosan-je) 위 험지구는 기존 위험등급이 $\mathrm{C}$ 등급으로 재해위험도가 낮게 산정되었으나, 실제로는 위험지구 면적 대비 범람 예상지역 면적비 0.87 로 홍수 위험지역이 상당히 편입되어있음을 확인하였다.

주민불편도 산정을 위한 하천재해위험지구 및 토지피복 도 주거지역, 집계구 경계 지도는 Fig. 4에 나타내었다. 일부 위험지구는 동두천시와 양주시 두 지자체에 겹쳐있기 때문 에 동두천시 집계구에 추가로 양주시의 집계구 경계 지도를 활용하였다. 주민불편도 비교결과 실제 주거지역을 반영한 인구밀도 산정 시 결과의 차이가 발생하는 것을 확인하였다. 예를 들어, 보산제(Bosan-je) 위험지구는 기존 방법론에 의한 인구밀도 산정 시 인구밀도가 13.00 명/ha으로 산정되었으나 개선안에 의한 실제 거주지역 반영 시 0 명/ha로 산정되었다. 즉, 보산제 위험지구에는 실제로는 거주하고 있는 주민이 없다는 것을 확인할 수 있다. 또한 송내천(Songnae-cheon) 위험지구의 경우 기존 방법론에 의한 인구밀도가 3.31 명/ha 에서 개선안에 의한 실제 거주지역 반영 시 21.20 명/ha로 증가하였다. 이는 실제 거주지역의 인구밀도 대비 집계구의 인구밀도가 적기 때문에 기존의 인구밀도가 과소산정 되었 음을 확인할 수 있다.

재해저감효과 산정결과는 Table 9에 나타내었다. 용도지 구 항목(Regional)이나 기반시설 항목(Infrastructure)은 편 입비율이 낮아 위험지구별 변별력이 낮았으며, 취약인구 항목(Human)과 오래된 건축물 비율 항목(Material)은 위험지
구별로 다르게 산정되어 변별력이 있었다. 봉동천(Bongdongcheon) 위험지구에서 취약인구가 가장 많이 집계되었으며 못골천(Motgol-cheon) 위험지구에서는 오래된 건축물의 비 율이 가장 높았다. 최종적으로 못골천 지구의 종합 재해저감 효과 지수가 가장 높게 산정되었다. 또한 거주인구수로부터 산정하는 항목인 주민불편도 항목과 취약인구 항목을 비교 한 결과 대체적으로 인구밀도가 높은 지구가 취약인구수가 높게 산정되었다. 이는 두 항목이 인구라는 공통된 지표를 평가하는 항목이기 때문에 발생한 결과로 볼 수 있다.

\section{2 하천재해위험지구 투자우선순위 결정}

기존의 평가짐수 산정기준에 의한 각 평가항목별 평가점 수와 표준화 및 정규화 및 각 평가항목별 신규 배점에 의한 개선안 평가점수를 합산한 결과는 Table 10 에 나타내었다. 먼저, 기존 평가점수 산정기준에 의하여 산정한 비용편익비 평가점수는 전체 20개소 위험지구 중 광암제1 (Gwangam-je 1) 위험지구를 제외하고는 모두 최고점인 15 점으로 산정되 었다. 이는 개선법에 의한 비용편익비 결과가 각 위험지구별 각기 다르게 산정되었음에도 불구하고 비용편익비가 3 이상 인 곳에 일괄적으로 최고점을 부여하기 때문이다. 이러한 방식은 평가요소의 변별력이 없기 때문에 위험지구별 투자 우선순위를 결정하는 데 있어서 적절하지 못한 방법으로 판단된다. 개선안에 의한 평가점수는 표준화 및 정규화로 인해 각 위험지구별 평가점수가 변별력 있게 분포되어있어 정량적으로 투자우선순위를 결정할 수 있다.

기존 방법론 및 개선한 방법론에 의해 산정한 평가점수를 종합하여 최종 투자우선순위를 도출한 결과는 Table 11에 나타내었다. 일부 위험지구에서는 기존의 투자우선순위를 유 
Table 9. Results of Disaster Reduction Effect to River Flooding Disaster Risk Zone

\begin{tabular}{|c|c|c|c|c|c|c|}
\hline No. & Name & Regional & Human & Material & Infrastructure & Total \\
\hline 1 & Sangbong-am 1 & 0.024 & 7.314 & 1.088 & 0 & 8.426 \\
\hline 2 & Anheung-je & 0.020 & 3.241 & 1.303 & 0 & 4.564 \\
\hline 3 & Seonup-songnae & 0.028 & 0 & 0 & 0 & 0.028 \\
\hline 4 & Bosan-je & 0.020 & 4.323 & 0.453 & 0 & 4.796 \\
\hline 5 & Sangpae-je 1 & 0.017 & 1.443 & 0.199 & 0 & 1.659 \\
\hline 6 & Dongdu-gol & 0.019 & 0.065 & 0.669 & 0 & 0.753 \\
\hline 7 & Sangpae-je 2 & 0.016 & 0.292 & 0.162 & 0 & 0.470 \\
\hline 8 & Sangpae-je 3 & 0.018 & 0.741 & 0.597 & 0 & 1.356 \\
\hline 9 & Gwangam-je 1 & 0.083 & 6.946 & 17.307 & 0 & 24.336 \\
\hline 10 & Gwangam-je 2 & 0.018 & 3.057 & 0.490 & 0 & 3.564 \\
\hline 11 & Gwangam-je 3 & 0.017 & 1.121 & 0.291 & 0 & 1.430 \\
\hline 12 & Gwangam-je 4 & 0.017 & 0.065 & 0.109 & 0 & 0.191 \\
\hline 13 & Motgol-cheon & 0.027 & 14.449 & 22.841 & 0.016 & 37.334 \\
\hline 14 & Songnae-cheon & 0.021 & 8.975 & 10.725 & 0 & 19.721 \\
\hline 15 & Anmal-cheon & 0.016 & 4.700 & 0.525 & 0 & 5.241 \\
\hline 16 & Yogol-cheon & 0.022 & 6.153 & 0.724 & 0 & 6.898 \\
\hline 17 & Dongmak-cheon & 0.025 & 20.941 & 1.812 & 0.033 & 22.812 \\
\hline 18 & Anheung-cheon & 0.028 & 18.921 & 1.772 & 0.043 & 20.715 \\
\hline 19 & Bongdong-cheon & 0.028 & 23.912 & 1.685 & 0.028 & 25.654 \\
\hline 20 & Saemal-cheon & 0.019 & 11.701 & 2.373 & 0 & 14.093 \\
\hline
\end{tabular}

Table 10. Evaluation Points of Existing Method and Improved Method

\begin{tabular}{|c|c|c|c|c|c|c|c|c|}
\hline \multirow{2}{*}{ No. } & \multirow{2}{*}{ Name } & \multicolumn{2}{|c|}{$\mathrm{B} / \mathrm{C}$} & \multicolumn{2}{|c|}{ Disaster risk } & \multicolumn{2}{|c|}{ Residents discomfort } & \multirow{2}{*}{$\frac{\text { Disaster reduction effect }}{\text { improved }}$} \\
\hline & & Existing & Improved & Existing & Improved & Existing & Improved & \\
\hline 1 & Sangbong-am 1 & 15 & 3.47 & 5 & 3.97 & 8 & 4.42 & 10.69 \\
\hline 2 & Anheung-je & 15 & 3.43 & 5 & 4.59 & 6 & 5.02 & 7.38 \\
\hline 3 & Seonup-songnae & 15 & 8.12 & 20 & 5.42 & 6 & 3.39 & 4.23 \\
\hline 4 & Bosan-je & 15 & 11.37 & 5 & 22.78 & 8 & 3.39 & 7.56 \\
\hline 5 & Sangpae-je 1 & 15 & 3.43 & 10 & 3.81 & 8 & 3.39 & 5.25 \\
\hline 6 & Dongdu-gol & 15 & 4.97 & 5 & 21.02 & 6 & 3.39 & 4.66 \\
\hline 7 & Sangpae-je 2 & 15 & 3.76 & 10 & 10.99 & 6 & 3.40 & 4.49 \\
\hline 8 & Sangpae-je 3 & 15 & 3.45 & 10 & 11.30 & 6 & 3.53 & 5.05 \\
\hline 9 & Gwangam-je 1 & 6 & 3.61 & 5 & 17.17 & 6 & 3.41 & 22.28 \\
\hline 10 & Gwangam-je 2 & 15 & 3.43 & 10 & 3.81 & 12 & 7.13 & 6.60 \\
\hline 11 & Gwangam-je 3 & 15 & 3.43 & 10 & 5.34 & 6 & 5.48 & 5.10 \\
\hline 12 & Gwangam-je 4 & 15 & 3.43 & 10 & 7.65 & 6 & 3.46 & 4.32 \\
\hline 13 & Motgol-cheon & 15 & 4.04 & 10 & 11.35 & 20 & 11.40 & 24.46 \\
\hline 14 & Songnae-cheon & 15 & 5.19 & 20 & 7.70 & 6 & 6.65 & 19.98 \\
\hline 15 & Anmal-cheon & 15 & 4.84 & 20 & 20.03 & 6 & 4.03 & 7.93 \\
\hline 16 & Yogol-cheon & 15 & 11.70 & 5 & 15.12 & 6 & 3.84 & 9.33 \\
\hline 17 & Dongmak-cheon & 15 & 3.84 & 5 & 9.06 & 6 & 7.78 & 21.64 \\
\hline 18 & Anheung-cheon & 15 & 4.26 & 20 & 17.29 & 6 & 4.69 & 20.57 \\
\hline 19 & Bongdong-cheon & 15 & 5.09 & 10 & 6.43 & 8 & 9.25 & 22.75 \\
\hline 20 & Saemal-cheon & 15 & 8.88 & 10 & 5.93 & 6 & 4.78 & 15.78 \\
\hline
\end{tabular}


Table 11. Investment Priority of Existing Method and Improved Method

\begin{tabular}{|c|c|c|c|c|c|c|}
\hline \multirow{2}{*}{ No. } & \multirow{2}{*}{ Name } & \multicolumn{2}{|c|}{ Total points } & \multicolumn{2}{|c|}{ Investment priority } & \multirow{2}{*}{ Rank variation } \\
\hline & & Existing & Improved & Existing & Improved & \\
\hline 1 & Sangbong-am 1 & 28 & 22.55 & 14 & 14 & 0 \\
\hline 2 & Anheung-je & 26 & 20.43 & 16 & 17 & -1 \\
\hline 3 & Seonup-songnae & 41 & 21.17 & 2 & 15 & -13 \\
\hline 4 & Bosan-je & 28 & 45.11 & 14 & 4 & +10 \\
\hline 5 & Sangpae-je 1 & 33 & 15.88 & 7 & 20 & -13 \\
\hline 6 & Dongdu-gol & 26 & 34.05 & 16 & 11 & +5 \\
\hline 7 & Sangpae-je 2 & 31 & 22.64 & 9 & 13 & -4 \\
\hline 8 & Sangpae-je 3 & 31 & 23.32 & 9 & 12 & -3 \\
\hline 9 & Gwangam-je 1 & 17 & 46.48 & 20 & 3 & +17 \\
\hline 10 & Gwangam-je 2 & 37 & 20.97 & 6 & 16 & -10 \\
\hline 11 & Gwangam-je 3 & 31 & 19.36 & 9 & 18 & -9 \\
\hline 12 & Gwangam-je 4 & 31 & 18.87 & 9 & 19 & -10 \\
\hline 13 & Motgol-cheon & 45 & 51.25 & 1 & 1 & 0 \\
\hline 14 & Songnae-cheon & 41 & 39.52 & 2 & 8 & -6 \\
\hline 15 & Anmal-cheon & 41 & 36.82 & 2 & 9 & -7 \\
\hline 16 & Yogol-cheon & 26 & 39.99 & 16 & 7 & +9 \\
\hline 17 & Dongmak-cheon & 26 & 42.32 & 16 & 6 & +10 \\
\hline 18 & Anheung-cheon & 41 & 46.82 & 2 & 2 & 0 \\
\hline 19 & Bongdong-cheon & 33 & 43.51 & 7 & 5 & +2 \\
\hline 20 & Saemal-cheon & 31 & 35.37 & 9 & 10 & -1 \\
\hline
\end{tabular}

지하거나 크게 변동이 없으나, 투자우선순위가 크게 비뀐 위험 지구도 나타났다. 전체적인 변동은 재해저감효과 항목의 추가 로 인한 변동 및 배점(가중치)의 변경 등이 주된 요인이었다. 광암제1 (Gwangam-je 1) 위험지구는 투자우선순위가 기존 20 위에서 3 위로 17 순위 상승하였다. 분석 결과 기존의 비용편 익비에 의한 평가점수의 변동은 크지 않으나 재해위험도 및 재해저감효과 항목에 의해 평가점수가 크게 상승하였다. 이는 광암제 1 위험지구는 범람 예상지역에 높은 비율 편입되어있으 며 재해 취약계층을 타 위험지구에 비해 높은 비율 반영하고 있기 때문이라 판단된다. 선업송내(Seonup-songnae) 위험지구 는 투자우선순위가 기존 2 위에서 15 위로 13 순위 하락하였다. 분석 결과 재해위험도에 의한 평가점수가 기존에는 최고점인 20 점이었으나 개선안에서는 5.42점으로 하위권의 점수를 부 여받았다. 비용편익비의 경우 개선안에서는 전체 위험지구 대비 중상위권의 점수이나 비용편익비 항목 자체의 가중치가 타 항목에 비해 낮다. 또한 가중치가 높은 재해저감효과 항목의 점수가 낮아 이러한 결과를 초래하였다고 판단된다.

\section{4. 결 론}

본 연구는 기존의 자연재해저감 종합계획 세부수립기준 에서 제시하는 자연재해위험지구, 특히 하천재해위험지구
를 중심으로 투자우선순위 결정기법의 문제점을 분석하고 문제점을 보완하는 개선안을 제시하였다. 기존의 투자우선 순위 결정기법과 개선안을 대상지역에 적용한 후 기존안투 자우선순위 대비 개선안에 의해 변동된 투자우선순위에 대한 원인 분석을 수행하였다. 분석 결과 개선한 하천재해위 험지구 투자우선순위 평가방법론 적용 결과 기존의 투자우 선순위와 차이가 발생하였다. 이는 신규 평가항목인 재해저 감효과의 도입이 가장 영향을 많이 미쳤으며, 가중치 재배치 및 평가점수 산정방법 변경 등에 의해서도 투자우선순위에 영향을 미쳤다. 그러나 본 연구에서 제시한 방법론에 의한 투자우순순위 결과가 기존 방법론에 의한 결과에 비해 더 타당한지 실질적인 검증이 필요하다. 이러한 투자우선순위 의 평가에 있어서 정확한 투자우선순위가 산정되었는지 평가하는 것은 많은 어려움이 있다. 그 이유는 전체 위험지구 에 동일한 강도의 재해가 발생하지 않는 이상 동등한 평가를 내릴 수 없기 때문이다. 동일한 강도의 재해가 전체 위험지구 에 발생할 확률은 매우 낮기 때문에 현실적으로 투자우선순 위의 사후평가는 난해한 실정에 있다. 이러한 한계점으로 인하여 본 연구에서는 기존 하천재해위험지구 투자우선순 위 결정기법의 문제점의 개선효과에 대하여 제시하였다.

기존의 하천재해위험지구 투자우선순위 결정기법의 문 제점 및 이에 대한 개선안을 다음과 같이 제시하였다. 
(1) 기존 경제성 분석을 위해 사용된 방법론인 개선법(회 귀분석법)은 침수심 및 침수기간, 홍수빈도를 고려하 지 못한다. 이에 따라 본 연구에서는 다차원법을 적용 하였다

(2) 재해위험도 평가항목 산정방법은 기존에는 위험지구 등급 항목과 과거 인명피해 발생여부 항목으로 나뉘는 데 두 항목 모두 타 평가항목과 중복될 우려가 있다. 이에 대한 개선법으로 본 연구에서는 홍수위험지도를 활용한 재해위험도 평가방법을 제시하였다.

(3) 주민불편도 평가항목 산정방법은 기존 위험지구로 지정된 지역에 해당되는 단순 집계구경계의 인구만을 반영하여 인구밀도를 산정하였으나, 개선안에서는 토지피복도를 활용하여 실제 주거지역을 반영하여 정확도 높은 인구밀도를 산정할 수 있도록 하였다.

(4) 기존의 지구선정 경과년수 평가항목은 지구로 선정된 이래로 오랜 기간이 지남에도 불구하고 정비되지 않고 있는 지구에 대해 높은 평가점수를 부여하고 있었으나 실효성이 결여된다는 문제점이 있다. 이에 본 연구에 서는 해당 평가항목을 대체하여 재해취약계층 및 용도 지구, 기반시설 등을 고려할 수 있는 재해저감효과 평가항목을 제시하였다.

(5) 기존의 모든 평가항목에 대한 평가점수 산정기준은 등급에 따라 점수를 부여하는데, 이러한 방식은 평가 의 변별력이 많이 낮으며 정량적인 투자우선순위 평가 가 어렵다. 이에 따라 본 연구에서는 표준화 및 정규화 를 활용한 상대평가에 의한 평가점수 산정방법을 적용 하였다.

(6) 기존 투자우선순위 평가방법을 개선함으로써 기존의 평가기준에서 제시한 각 평가항목별 배점을 개선한 평가항목에 맞춰 배점(가중치)를 재산정하였다. 가중 치는 AHP 분석기법을 통해 산정하였다.

본 연구에서 제시한 하천재해위험지구 투자우선순위 결 정기법은 향후 시·군 자연재해저감종합계획 세부수립기 준의 자연재해위험지구 투자우선순위 결정 시 활용되어 정량적이며 효과적인 자연재해위험지구 정비사업 계획을 수립할 수 있을 것으로 기대된다. 또한, 정량적인 자연재해 위험지구 투자우선순위의 결정으로 인해 한정된 재해예방 사업비를 효과적이고 효율적으로 배분할 수 있을 것으로 기대된다.

\section{감사의 글}

본 연구는 행정안전부의 재원으로 재난예측및저감연구개 발사업의 지원을 받아 수행된 연구임[MOIS-재난-2015-05].

이 논문은 2018년도 인하대학교의 지원에 의하여 연구되 었음(INHA-57822).

\section{References}

Aerts, J.C., Botzen, W.J., Clarke, K.C., Cutter, S.L., Hall, J.W., Merz, B. et al. (2018). Integrating human behaviour dynamics into flood disaster risk assessment. Nature Climate Change, Vol. 8, No. 3, pp. 193-199.

Choi, B.H., and Lee, B. (2015). Investment priorities for the decision-making support based on the evaluation of downstream areas and surrounding of dam. $J$. Korean Soc. Hazard Mitig., Vol. 15, No. 1, pp. 305-313.

Choi, S.A., Yi, C.S., Shim, M.P., and Kim, H.S. (2006). Multi-dimensional flood damage analysis (I): Principle and procedure. Journal of Korea Water Resources Association, Vol. 39, No. 1, pp. 1-9.

Heo, B.Y., Yu, S., and Kim, S.W. (2013). Economic impact analysis of disaster mitigation projects in hazardous areas. Economic and Environmental Geology, Vol. 46, No. 3, pp. 247-256.

Joo, H., Kim, S., Lee, M., and Kim, H. (2018). A study on determination of investment priority of flood control considering flood vulnerability. J. Korean Soc. Hazard Mitig., Vol. 18, No. 2, pp. 417-429.

Kim, H.Y., and Lee, S.J. (2017). Analysis on officials' and experts' perception of local hazard prevention policies and key factors of natural hazard mitigation project. Seoul Studies, Vol. 18, No. 3, pp. 73-83.

Kim, M.K., Kim, J.B., and Bae, D.H. (2018). Development of the water disaster vulnerability index and evaluation of water disaster vulnerability in the Asian monsoon region. J. Korean Soc. Hazard Mitig., Vol. 18, No. 7, pp. 457-467.

Kim, W.G., Lee, G.M., and Park, D.H. (2006). Investment ranking decision using MCDA in dam projects. Journal of Korea Water Resources Association, Vol. 39, No. 12, pp. 1067-1080.

Lee, J.H., Jung, P., Rhie, J., Roh, J., and Won, J.U. (2013). Evaluations of industrial accident prevention program of Korea by using analytic hierarchy process (AHP) method. Journal of the Korea Safety Management and Science, Vol. 15, No. 4, pp. 55-61.

Loos, J., and Rogers, S. (2016). Understanding stakeholder preferences for flood adaptation alternatives with natural capital implications. Ecology and Society, Vol. 21, No. 3, Article No. 32. doi:10.5751/ES08680-210332 
Ministry of the Interior and Safety (MOIS). (2018). Standards of the comprehensive plan for Storm flood damage reduction.

Ryu, J., and Han, S. (2016). Determining the priority of investment by risk assessment for slopes. J. Korean Soc. Hazard Mitig., Vol. 16, No. 3, pp. 161-170.

Saaty, T.L. (1997). A scaling method for priorities in hierarchical structures. Journal of Mathematical Psychology, Vol. 15, No. 3, pp. 243-281.

\begin{tabular}{|l|l|}
\hline Received & October 13, 2019 \\
\hline Revised & October 15, 2019 \\
\hline Accepted & November 12, 2019 \\
\hline
\end{tabular}

